\title{
Clinical and Laboratory Characteristics of Herpes Simplex Encephalitis in Children in Qena Governorate, Egypt
}

\author{
Eman M. Salah Eldinª, Sanaa Shaker Alyb ${ }^{\mathrm{b}}$ Zainab M.Mohey El-Deen ${ }^{\mathrm{c}}$, Ahmed E. Ahmed ${ }^{\mathrm{d}}$, \\ Ismail Lotfy Mohamad, e
}

\begin{abstract}
Background: Herpes encephalitis in children entails a significant risk of mortality and morbidity. The diagnosis of herpes simplex virus (HSV) encephalitis has been markedly facilitated by the availability of assays that amplify viral DNA to detectable levels by using polymerase chain reaction (PCR). This study aimed to obtain the incidence of HSV encephalitis in Qena Governorate, Egypt, to highlight the role of different investigation studies in diagnosis and prognosis of herpetic encephalitis and to highlight the role of PCR in detection of HSV.
\end{abstract}

Methods: This study was conducted on 50 patients suspected to have viral encephalitis. All were subjected to complete history and examination, cerebrospinal fluid (CSF) examination, electroencephalogram (EEG), CT brain and PCR amplification for HSV DNA by real-time PCR using SYBR Green I Dye as the detection signal.

Results: Encephalitis was more detected in cases less than 1 year $(52.2 \%)$, males, in rural $(61.3 \%)$ and in lower socioeconomic state $(55 \%)$ than others. Seizures $(60 \%)$ and focal neurological findings (46\%) were the most common presentations. HSV DNA was detected by PCR in CSF samples from 28 patients $(56 \%)$.

Conclusions: PCR may be one of the sensitive and specific investigative methods for laboratory diagnosis of HSV encephalitis. The incidence of HSV-induced encephalitis in children in Qena governorate was $56 \%$.

Keywords: Herpes simplex; Encephalitis; Children

Manuscript submitted April 13, 2017, accepted June 22, 2017

${ }^{a}$ Clinical Pathology Department, Faculty of Medicine, Assuit University, Egypt

${ }^{b}$ Clinical Pathology Department, Qena Faculty of Medicine, South Valley University, Egypt

'Pediatrics Department, Faculty of Medicine, Assiut University, Egypt

dPediatrics Department, Faculty of Medicine, South Valley University, Egypt

${ }^{e}$ Corresponding Author: Ismail Lofty Mohamad, Pediatrics Department, Fac-

ulty of Medicine, Assiut University, Assiut 71516, Egypt.

Email:drsomaa@yahoo.com

doi: https://doi.org/10.14740/ijcp274w

\section{Introduction}

Encephalitis is defined as inflammation of the brain parenchyma associated with neurologic dysfunction [1]. Herpes simplex encephalitis (HSE) is due to the herpes simplex virus (HSV) 1 or 2 in the central nervous system (CNS) and it is the most frequent cause of infectious encephalitis worldwide. For many CNS infections that are treatable, there is a need for a rapid and accurate diagnostic test for HSV encephalitis. Prompt diagnosis and aggressive management afford the best chance of recovery without squeals [2]. Polymerase chain reaction (PCR) testing of cerebrospinal fluid (CSF) has become the diagnostic method of choice for CNS viral infections replacing the use of invasive brain biopsy [3]. Although testing is expensive, there is a potential for cost savings by decreasing overall diagnostic testing and intervention [4]. PCR for HSV DNA performed on CSF is now considered to be the reference standard for establishing the diagnosis of HSE from the first days of the disease and has been widely accepted for routine clinical decision making $[5,6]$. This study aimed to obtain the incidence of HSV in Qena Governorate, Egypt, to highlight the role of different investigation studies in diagnosis and prognosis of herpetic encephalitis and to highlight the role of PCR in detection of HSV.

\section{Methods}

This study was conducted on 50 patients who were admitted to Qena University Hospital and Qena Fever Hospital during the period of January 2016 to January 2017. Children suspected to have viral encephalitis were included as any child was admitted to the hospital with encephalopathy (altered level of consciousness persisting for more than $24 \mathrm{~h}$ with lethargy, irritability or a change in personality and behavior) and two or more of the following: fever or history of fever $\left(\geq 38^{\circ} \mathrm{C}\right)$, seizures and focal neurological findings (with evidences of brain parenchyma involvement), CSF pleocytosis, electroencephalogram (EEG) findings suggestive of encephalitis and abnormal results of neuro-imaging in keeping with encephalitis. Patients with non-infectious CNS disorders due to hypoxia, ischemia, vascular, toxic, and metabolic causes and patients with CNS disorders lasting less than $24 \mathrm{~h}$ were excluded from the study. All patients were subjected to complete history taking includ- 
Table 1. Demographic Data of the Patients With Encephalitis

\begin{tabular}{lll}
\hline Demographic data & $\mathbf{N}=\mathbf{5 0}$ & $\mathbf{\%}$ \\
\hline Age & & \\
$\quad<1$ year & 23 & 46.0 \\
$\quad 1-5$ years & 17 & 34.0 \\
$\quad>5$ years & 10 & 20.0 \\
Sex & & \\
$\quad$ Male & 29 & 58.0 \\
$\quad$ Female & 21 & 42.0 \\
Residence & \\
$\quad$ Urban & 19 & 38.0 \\
$\quad$ Rural & 31 & 62.0 \\
Socioeconomic status & & \\
$\quad$ Low & 20 & 40.0 \\
$\quad$ Middle & 17 & 34.0 \\
$\quad$ High & 13 & 26.0 \\
\hline
\end{tabular}

ing socioeconomic state according to the scale of El-Gilany et al (2012) [7], complete physical and neurological examination, EEG and CT brain. The study was approved by the Ethical and Research Committees. An informed written consent in accordance was taken from all cases.
Table 2. Neurological Presentation of the Patients With Encephalitis

\begin{tabular}{lll} 
& $\mathbf{N}=\mathbf{5 0}$ & $\mathbf{\%}$ \\
\hline Lethargy & 9 & 18.0 \\
Behavioral changes & 16 & 32.0 \\
Seizure & 30 & 60.0 \\
Neck stiffness & 21 & 42.0 \\
Focal neurological finding & 23 & 46.0 \\
GCS $<10$ & 26 & 52.0 \\
\hline
\end{tabular}

CSF by lumber puncture with proper aseptic precautions from all patients with clinical suspicion of encephalitis was obtained and subjected to physical, cytological and chemical examinations. A blood sample for glucose was taken at the same time of CSF collection. The DNA was extracted from CSF using DNA isolation kit (cat. no. 2032805; QIAGEN, Hilden, Germany) according to the manufacturer's instructions. DNA extracted from each sample was processed with two different sets of primers, amplifying regions from thymidine kinase (Tk; 335 bp) (Tk-forward, GAC MAG CGC CCA GAT AAC AA; Tk-reverse, MCA GCA TRG CCA GGT CAA GC (GenBank accession no. M16321), and DNA polymerase (Pol; 215 bp) (Pol-forward, GCT CGA GTG CGA AAA AAC GTTC; Polreverse, CGG GGC GCT CGG CTA AC (GenBank accession

Table 3. Demographic Characteristics in Relation to PCR

\begin{tabular}{|c|c|c|c|c|c|}
\hline & \multicolumn{4}{|c|}{ PCR } & \multirow{3}{*}{ No. of total cases (50) } \\
\hline & \multicolumn{2}{|c|}{ Positive $(\mathrm{N}=28)$} & \multicolumn{2}{|c|}{ Negative $(\mathrm{N}=\mathbf{2 2})$} & \\
\hline & No. & $\%$ & No. & $\%$ & \\
\hline \multicolumn{6}{|l|}{ Age (years) } \\
\hline$<1$ & 12 & 52.2 & 11 & 47.8 & 23 \\
\hline $1-5$ & 10 & 58.8 & 7 & 41.2 & 17 \\
\hline$>5$ & 6 & 60.0 & 4 & 40.0 & 10 \\
\hline P-value & NS & & & & \\
\hline \multicolumn{6}{|l|}{ Sex } \\
\hline Male & 11 & 37.9 & 18 & 62.1 & 29 \\
\hline Female & 17 & 81.0 & 4 & 19.0 & 21 \\
\hline P-value & $<0.05^{*}$ & & & & \\
\hline \multicolumn{6}{|l|}{ Residence } \\
\hline Urban & 9 & 47.4 & 10 & 52.6 & 19 \\
\hline Rural & 19 & 61.3 & 12 & 38.7 & 31 \\
\hline P-value & NS & & & & \\
\hline \multicolumn{6}{|c|}{ Socioeconomic state } \\
\hline Low & 11 & 55.0 & 9 & 45.0 & 20 \\
\hline Middle & 9 & 52.9 & 8 & 47.1 & 17 \\
\hline High & 8 & 61.5 & 5 & 38.5 & 13 \\
\hline P-value & NS & & & & \\
\hline
\end{tabular}


Table 4. Neuroimaging and EEG Findings in Relation to Herpes Simplex Encephalitis According to PCR

\begin{tabular}{|c|c|c|c|c|c|}
\hline \multirow{3}{*}{ Neuroimaging findings } & \multicolumn{4}{|c|}{ PCR } & \multirow{3}{*}{ No. of total cases (50) } \\
\hline & \multicolumn{2}{|c|}{ Positive $(\mathrm{N}=28)$} & \multicolumn{2}{|c|}{ Negative $(\mathrm{N}=22)$} & \\
\hline & No. & $\%$ & No. & $\%$ & \\
\hline \multicolumn{6}{|l|}{ CT } \\
\hline Abnormal findings* & 12 & 80.0 & 3 & 20.0 & 15 \\
\hline Normal & 16 & 45.7 & 19 & 54.3 & 35 \\
\hline P-value & $<0.05^{*}$ & & & & \\
\hline \multicolumn{6}{|l|}{ EEG } \\
\hline Abnormal findings* & 22 & 55.0 & 18 & 45.0 & 40 \\
\hline Normal & 6 & 60.0 & 4 & 40.0 & 10 \\
\hline P-value & NS & & & & \\
\hline
\end{tabular}

no. X03764 and X01712). For the assay, in a final $20 \mu \mathrm{L}$ reaction volume in capillary tubes, $1.0 \mu \mathrm{L}$ of extracted DNA was added to $2.0 \mu \mathrm{L}$ Fast Start SYBR Green I Master Mix (Roche), $1.6 \mu \mathrm{L} \mathrm{MgCl}_{2}, 1 \mu \mathrm{L}$ of primer and $14.4 \mu \mathrm{L}$ water. The capillary tubes were taken into the light cycler instrument, Roche Diagnostic (version 3, 5) using SYBR Green I Dye as the detection signal and amplified as follows: $95{ }^{\circ} \mathrm{C}$ for $7 \mathrm{~min}$ followed by 50 cycles of $95^{\circ} \mathrm{C}$ for $30 \mathrm{~s}, 62^{\circ} \mathrm{C}$ for $10 \mathrm{~s}$, and $72{ }^{\circ} \mathrm{C}$ for 12 s. Melting curve analysis for HSV was done by denaturation of amplification samples by slow increase of temperature $\left(0.2^{\circ} \mathrm{C} / \mathrm{s}\right)$ up to $99^{\circ} \mathrm{C}$. Sequence differences between the PCR products resulted in shifts in the melting temperatures $\left(66.7^{\circ} \mathrm{C}\right.$ for $\mathrm{HSV}-1$ and $74.7^{\circ} \mathrm{C}$ for HSV-2 which were detected).

\section{Statistical analysis}

SPSS version 16 was used to analyze the obtained data, descriptive statistics was used to calculate the percentage, $t$-test was used for comparing numerical data and Chi-squared test was used for categorical data.

\section{Results}

This study was conducted on 50 patients who were admitted to Qena University Hospital and Qena Fever Hospital and suspected to have viral encephalitis.

Demographic and neurological data of patients are shown in Tables 1 and 2.

Regarding CSF findings, patients with HSV encephalitis typically have moderate elevation of CSF opening pressure, a moderate CSF pleocytosis, a mildly elevated CSF protein and normal CSF to plasma glucose ratio. HSV DNA was detected by PCR in CSF samples from 28 patients $(28 / 50,56 \%)$ and were negative in $22 / 50(44 \%)$.

On studying the demographic characteristics in relation to PCR, we found that positive PCR was detected in $52.2 \%$ of cases aged less than 1 year, in $58.8 \%$ of cases aged $1-5$ years and in $60 \%$ of cases aged more than 5 years $(\mathrm{P}>0.05)$.
According to the sex, positive PCR was detected in $37.9 \%$ of male cases and in $81 \%$ of female cases $(\mathrm{P}<0.05)$. According to the residence, $61.3 \%$ of rural area patients showed positive PCR as compared to $52.6 \%$ of urban area patients $(\mathrm{P}>0.05)$. According to the socioeconomic state, among 20 cases belonging to low socioeconomic state, $11(55 \%)$ cases had positive PCR and nine (45\%) cases had negative PCR. While among 17 cases belonging to middle socioeconomic state, nine $(52.9 \%)$ cases had positive PCR and eight (47.1\%) cases had negative PCR and among 13 cases belonging to high socioeconomic state, eight $(61.5 \%)$ cases had positive PCR and five $(38.5 \%)$ cases had negative PCR ( $\mathrm{P}>0.05)$, as in Table 3 .

Neuroimaging and EEG findings in relation to HSE according to PCR, showed that among 15 cases with abnormal CT findings, 12 cases $(80 \%)$ had positive PCR and three cases $(20 \%)$ had negative PCR and among 35 cases with normal CT findings, 16 cases (45.7\%) had positive PCR and 19 cases $(54.3 \%)$ had negative PCR $(\mathrm{P}<0.05)$. While among 40 cases with abnormal EEG findings, 22 cases $(55 \%)$ had positive PCR and 18 cases (45\%) had negative PCR and among 10 cases with normal EEG findings, six cases $(60 \%)$ had positive PCR and four cases $(40 \%)$ had negative PCR $(\mathrm{P}>0.05)$, as in Table 4.

Sensitivity and specificity of PCR to Glasgow coma scale (GCS), EEG and CT showed that sensitivity of GCS $<10$ was $57.69 \%$ (low sensitive) and specificity was $45.83 \%$ (nonspecific), sensitivity of EEG was $45 \%$ (non-sensitive) and specificity was $60 \%$ (specific), and sensitivity of CT was $80 \%$ (highly sensitive) and specificity was $54.29 \%$ (low specific)

Table 5. Sensitivity and Specificity of PCR to GCS, EEG, and CT

\begin{tabular}{llll}
\hline & GCS $<$ 10 & EEG & CT \\
\hline Sensitivity & $57.69 \%$ & $45.0 \%$ & $80.0 \%$ \\
Specificity & $45.83 \%$ & $60.0 \%$ & $54.29 \%$ \\
Positive predictive value & $53.6 \%$ & $81.8 \%$ & $42.9 \%$ \\
Negative predictive value & $50.0 \%$ & $21.4 \%$ & $86.4 \%$ \\
Area under curve (AUC) & 0.518 & 0.525 & 0.671 \\
\hline
\end{tabular}




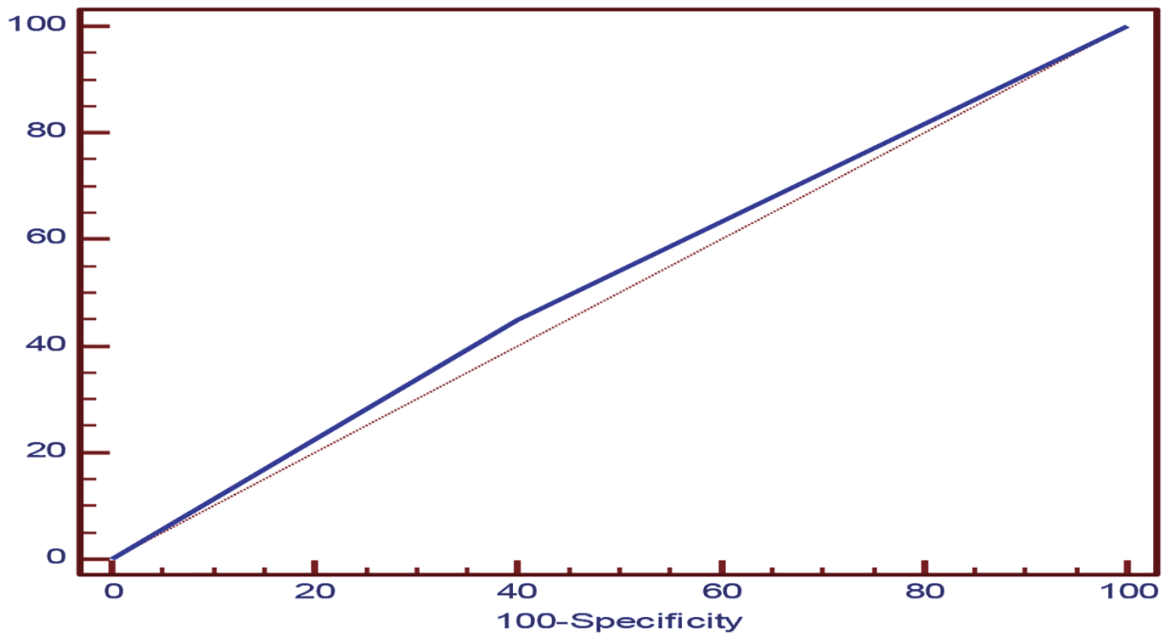

Figure 1. Curve shows the sensitivity and specificity of EEG.

(Table 5, Figs. 1-3).

\section{Discussion}

Viral encephalitis is a medical emergency. The severity of brain involvement and the prognosis depend mainly on the specific pathogen and the immunological state of the host [8]. Despite of advances in antiviral therapy over the past two decades, HSV encephalitis has yet remained as a serious illness with significant risks of morbidity and death [9]. HSV is an important cause of acute necrotizing encephalitis, with an incidence of 1 in 250,000 to 1 in 500,000 [10]. Whereas in the past, brain biopsy was the gold standard for diagnosis of HSE, PCR is now the preferred diagnostic test despite the possibility of false-positive and false-negative results [11]. False-negative CSF PCR may be encountered if the CSF is collected too early (first 24 - 48 h) or too late (after 10 - 14 days) [12].

From all 50 patients presenting with neurological manifestations that suggested viral encephalitis, only 28 cases $(56 \%)$ had positive PCR for HSV, while 22 cases (44\%) had negative PCR for herpes simplex. A report from England which shows the incidence of HSV was $19 \%$ in patients with encephalitis [13]. However, a report from France shows that the most frequent etiologic agent of encephalitis was HSV [14] and another report from Babol, a northern city in Iran, reported HSV positive in a high rate $(34 \%)$ of patients with encephalitis [15]. Also, in Taiwan HSV is still considered as the main viral source of encephalitis [12]. However, a study from Spain indicated that HSV was positive in $27.6 \%$ of patients hospitalized with encephalitis [16].

In the present study, age has no significant effect on the result of PCR, and this result was in accordance with those of Xavier et al [17] who reported that in a retrospective study of

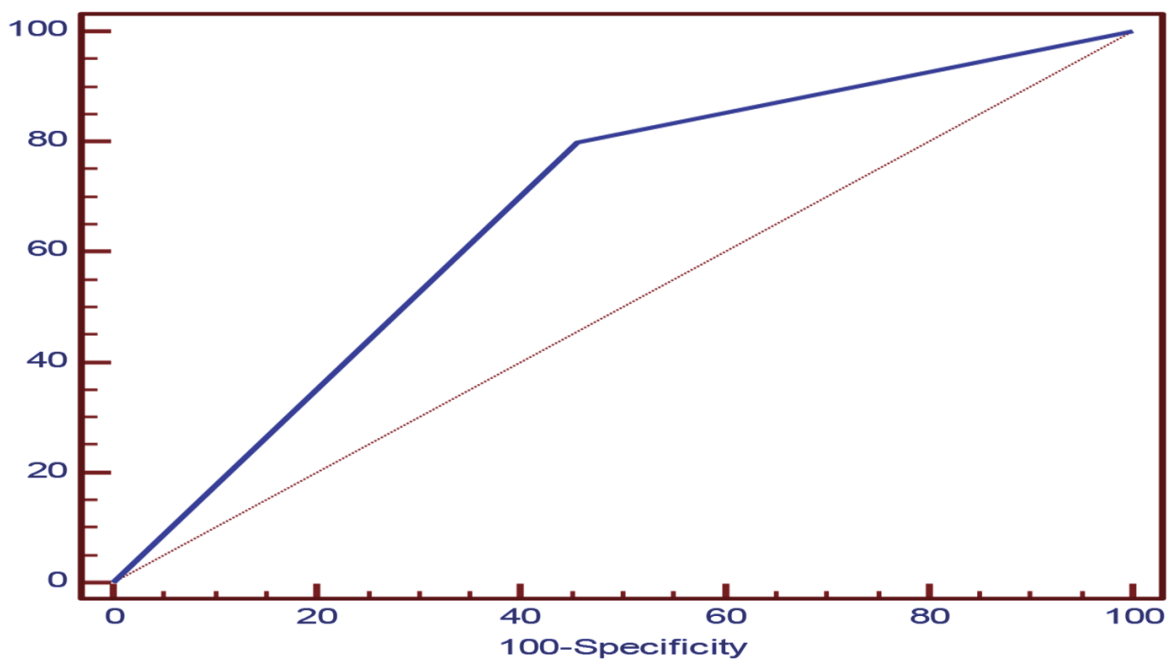

Figure 2. Curve shows the sensitivity and specificity of CT. 


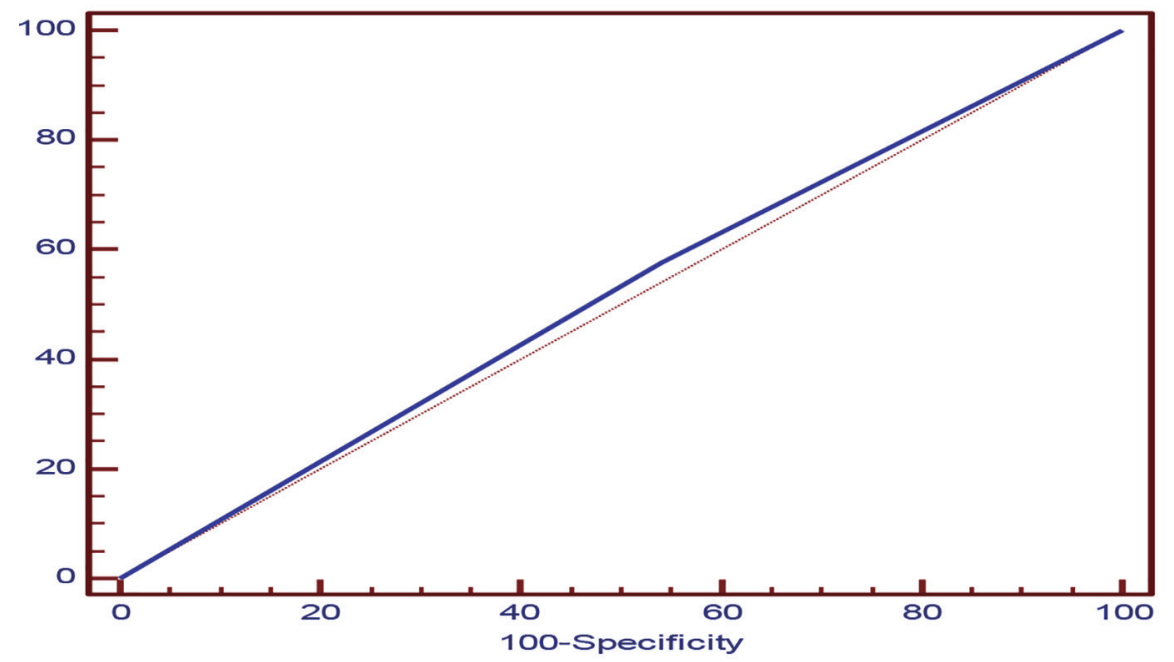

Figure 3. Curve shows the sensitivity and specificity of GCS $<10$.

38 cases, $16(42 \%)$ were aged 3 - 12 months, eight (21\%) were aged 1 - 3 years, and $14(37 \%)$ were aged 5 - 16 years. Furthermore, in an Iranian study, Masoud et al [18] documented that age was a non-significant factor in the patients with HSV encephalitis. According to the sex, in our study female patients showed significant high frequency of positive PCR in comparison to male patients. In contrast to our study, Cai et al [19] documented that the rate of positivity of virus detection in children was higher in boys than in girls. A recent report of HSE in children also described more cases in boys than girls [20]. Epidemiological studies of HSE in adults showed an equal distribution among male and female patients [21, 22]. However, larger study should be required to confirm this result.

In the present study, according to the residence, HSV occurs in rural patients more than urban patients. According to the socioeconomic state, HSV encephalitis occurs more among low socioeconomic state. The frequency of occurrence of encephalitis in children of rural resident areas and economically poor families may be explained by exposure of children of these families to inadequate breast feeding, improper weaning practice, low rate of use of safe water and sanitary latrines which aggravate malnutrition as a host factor to be infected by viruses [23]. Neuroimaging findings and EEG in relation to HSE showed that among 15 cases $(30 \%)$ with abnormal CT findings, 12 cases $(80 \%)$ had positive PCR and three cases (20\%) had negative PCR and among 35 cases with normal CT findings, 16 cases $(45.7 \%)$ had positive PCR and 19 cases (54.3\%) had negative PCR, which indicates that abnormal CT finding was significantly higher among patients with positive PCR. In an earlier study published in 1997 [24], 33.3\% of patients with PCR-positive HSV encephalitis had a normal CT of the brain and two-thirds of the rest had a temporal abnormality. By Renan et al's study [24], HSV DNA was detected in CSF samples from $18(36.7 \%)$ of 49 patients. Forty-eight patients underwent $\mathrm{CT}$ of the brain in which temporal abnormalities were found in $44.5 \%$ of the PCR-positive cases and $6.7 \%$ of the PCR-negative cases. By many authors, MRI is much more sensitive especially for detecting early changes [25-28]. The
EEG may show focal or diffuse slowing, focal sharp waves or spikes or periodic lateralized epileptiform discharges, but no pattern is pathognomonic for HSE [29, 30]. In our study, abnormal EEG was seen in $80 \%$ of cases. While among 40 cases with abnormal EEG findings, 22 (55\%) cases had positive PCR and 18 (45\%) cases had negative PCR and among 10 cases with normal EEG findings, six $(60 \%)$ cases had positive PCR and four (40\%) cases had negative PCR (P>0.05). In AlShekhlee et al's study [31], periodic lateralized epileptiform discharges and/or focal temporal slowing were present in $90 \%$ of the PCR-positive patients at symptom onset compared with only $30 \%$ of the PCR-negative group. By others [32], EEG abnormalities were detected in $94 \%$ of children with HSE. These consisted of non-specific diffuse slow waves in four (24\%) patients and focal slow waves in $13(76 \%)$ patients. However, there has been no significant association between the presence of EEG abnormalities and a positive PCR result for HSV in the CSF. Our results showed that in relation to positive PCR, GCS $<10$ had sensitivity of $57.7 \%$ (low sensitive) and specificity of $45.8 \%$ (non-specific), while EEG had sensitivity of $45.0 \%$ (low sensitive) and specificity of $60.0 \%$ (high specific); also, CT had sensitivity of $80.0 \%$ (high sensitive) and specificity of $54.29 \%$ (low specific) (Table 5). In previous studies, PCR assays performed on specimens from patients with brain biopsyproven HSE reveal a diagnostic sensitivity of $98 \%$ at the time of clinical presentation as well as a specificity approaching $100 \%$ [33]. Of note, negative PCR assay for HSV DNA on the first or second day of illness may become positive on testing of a subsequent CSF specimen [10]. By Domingues et al's studies $[24,25]$, there were $79 \%$ of patients with HSV encephalitis showing abnormalities on their initial CT scan, but $100 \%$ of the other patients whose CT scan was initially normal showing abnormalities an average of 5 days later on repetition of scans. In HSE cases in which viral replication cannot be blocked with early treatment, surviving patients are known to suffer heavy and large number of neurological squeals. Therefore, early diagnosis is of great importance. Diagnosis is made with clinical symptoms, MRI, EEG, and CSF examination. The sensitivity 
is increased with the combination of these neurodiagnostic tests, but the specificity is still insufficient $[34,35]$.

Our study had several limitations; false negatives can occur due to testing too early or too late. PCR was done once for each case as a single negative PCR does not exclude HSE. Small number of cases included in our study is considered as another limitation. A uniform, validated HSV PCR assay providing quantitative data is necessary to further study the pathogenesis of herpes infections particularly for evaluation of the evolution and outcomes of HSV CNS infections. A multicenter evaluation of PCR in HSV encephalitis should be undertaken in hopes of achieving high sensitivity and specificity of the assay.

\section{Conclusions}

We concluded that PCR is the most sensitive and specific investigative method for diagnosis of HSE. The incidence of HSV-induced encephalitis in children in Qena Governorate was $56 \%$. The disease was more common in children aged less than 1 year than in older children. HSV CNS infection must always be considered in children presenting with convulsions even without encephalopathy and with normal CT findings. We recommended future advances in the understanding of HSE pathophysiology and the immunological consequences of HSV cerebral infection that could lead to a better delineation of the clinical spectrum of HSE in children and to more appropriate and specific therapeutic strategies. Further studies on a wide scale are needed to verify the epidemiology of viral encephalitis in the South Valley area to determine the outcome of these patients and the effect of early antiviral therapy on the outcome of these patients.

\section{Acknowledgments}

We acknowledge Professor Hoseny Badrawy Hamed, at Oncological Clinical Pathology Department, South Egypt Cancer Institute, Assuit University, Egypt for his help in practical work.

\section{Funding Source}

No grant, honorarium, or other form of payment was given to authors to produce this manuscript.

\section{Financial Disclosure}

The authors have no financial relationships relevant to this article to disclose.

\section{Conflicts of Interest}

All authors do not have potential conflict of interest.

\section{References}

1. Tunkel AR, Glaser CA, Bloch KC, Sejvar JJ, Marra CM, Roos KL, Hartman BJ, et al. The management of encephalitis: clinical practice guidelines by the Infectious Diseases Society of America. Clin Infect Dis. 2008;47(3):303327.

2. Marra CM, Whitley RJ, Scheld WM. Approach to the patient with central nervous system infection; 1. In: W. Michael Scheld, Richard J. Whitley, Christina M. Marra. Infections of the central nervous system, 3rd ed. Philadelphia, United States: Lippincott Williams \& Wilkins. 2004. p. 1-4.

3. Kimberly E. Hanson, Barbara D. Alexander, Christopher Woods, Cathy Petti, Barth L. Reller. Infections of the central nervous system. 2007;721-724.

4. Cinque P, Scarpellini P, Vago L, Linde A, Lazzarin A. Diagnosis of central nervous system complications in HIV-infected patients: cerebrospinal fluid analysis by the polymerase chain reaction. AIDS. 1997;11(1):1-17.

5. Cinque P, Cleator GM, Weber T, Monteyne P, Sindic CJ, van Loon AM. The role of laboratory investigation in the diagnosis and management of patients with suspected herpes simplex encephalitis: a consensus report. The EU concerted action on virus meningitis and encephalitis. J Neurol Neurosurg Psychiatry. 1996;61(4):339-345.

6. Whitley RJ, Gnann JW. Viral encephalitis: familiar infections and emerging pathogens. Lancet. 2002;359(9305): 507-513.

7. El-Gilany A, El-Wehady A, El-Wasify M. Updating and validation of the socioeconomic status scale for health research in Egypt. East Mediterr Health J. 2012;18(9):962968.

8. Steiner I, Budka H, Chaudhuri A, Koskiniemi M, Sainio K, Salonen O, Kennedy PG. Viral encephalitis: a review of diagnostic methods and guidelines for management. Eur J Neurol. 2005;12(5):331-343.

9. Behzad-Behbahani A, Abdolvahab A, Gholamali YP, Roshanak B, Mahmood R. Clinical signs as a guide for performing HSV-PCR in correct diagnosis of herpes simplex virus encephalitis. Neurol India. 2003;51(3):341-344.

10. Weil AA, Glaser CA, Amad Z, Forghani B. Patients with suspected herpes simplex encephalitis: rethinking an initial negative polymerase chain reaction result. Clin Infect Dis. 2002;34(8):1154-1157.

11. Rowley AH, Whitley RJ, Lakeman FD, Wolinsky SM. Rapid detection of herpes-simplex-virus DNA in cerebrospinal fluid of patients with herpes simplex encephalitis. Lancet. 1990;335(8687):440-441.

12. Chaudhuri A, Kennedy PG. Diagnosis and treatment of viral encephalitis. Postgrad Med J. 2002;78(924):575583.

13. Ambrose HE, Granerod J, Clewley JP, Davies NW, Keir G, Cunningham R, Zuckerman M, et al. Diagnostic strategy used to establish etiologies of encephalitis in a prospective cohort of patients in England. J Clin Microbiol. 2011;49(10):3576-3583.

14. Whitley RJ, Cobbs CG, Alford CA, Jr., Soong SJ, Hirsch 
MS, Connor JD, Corey L, et al. Diseases that mimic herpes simplex encephalitis. Diagnosis, presentation, and outcome. NIAD Collaborative Antiviral Study Group. JAMA. 1989;262(2):234-239.

15. Kwok S, Higuchi R. Avoiding false positives with PCR. Nature. 1989;339(6221):237-238.

16. de Ory F, Avellon A, Echevarria JE, Sanchez-Seco MP, Trallero G, Cabrerizo M, Casas I, et al. Viral infections of the central nervous system in Spain: a prospective study. J Med Virol. 2013;85(3):554-562.

17. De Tiege X, Heron B, Lebon P, Ponsot G, Rozenberg F. Limits of early diagnosis of herpes simplex encephalitis in children: a retrospective study of 38 cases. Clin Infect Dis. 2003;36(10):1335-1339.

18. Ghannad MS, Solgi G, Hashemi SH, Zebarjady-Bagherpour J, Hemmatzadeh A, Hajilooi M. Herpes simplex virus encephalitis in hamadan, iran. Iran J Microbiol. 2013;5(3):272-277.

19. Cai XY, Lu XD, Lin GY, Cai ZW, Lin CX, Chen PZ, Zheng YL, et al. [Monitoring of viral pathogens in pediatric intensive care unit and analysis of clinical significance]. Zhonghua Er Ke Za Zhi. 2013;51(6):453-459.

20. Misra UK, Tan CT, Kalita J. Viral encephalitis and epilepsy. Epilepsia. 2008;49(Suppl 6):13-18.

21. Studahl M, Hagberg L, Rekabdar E, Bergstrom T. Herpesvirus DNA detection in cerebral spinal fluid: differences in clinical presentation between alpha-, beta-, and gamma-herpesviruses. Scand J Infect Dis. 2000;32(3):237248.

22. Powell KF, Anderson NE, Frith RW, Croxson MC. Noninvasive diagnosis of herpes simplex encephalitis. Lancet. 1990;335(8685):357-358.

23. Wahed MA, Sarker PC, Hossain MA. Encephalitis in children A three-year experience in a teaching hospital. The ORION Medical Journal. 2010;33(1):707-709.

24. Domingues RB, Tsanaclis AM, Pannuti CS, Mayo MS, Lakeman FD. Evaluation of the range of clinical presentations of herpes simplex encephalitis by using polymerase chain reaction assay of cerebrospinal fluid samples. Clin Infect Dis. 1997;25(1):86-91.

25. Domingues RB, Fink MC, Tsanaclis AM, de Castro CC,
Cerri GG, Mayo MS, Lakeman FD. Diagnosis of herpes simplex encephalitis by magnetic resonance imaging and polymerase chain reaction assay of cerebrospinal fluid. $\mathrm{J}$ Neurol Sci. 1998;157(2):148-153.

26. Marchbank ND, Howlett DC, Sallomi DF, Hughes DV. Magnetic resonance imaging is preferred in diagnosing suspected cerebral infections. BMJ. 2000;320(7228):187188.

27. Dale RC, de Sousa C, Chong WK, Cox TC, Harding B, Neville BG. Acute disseminated encephalomyelitis, multiphasic disseminated encephalomyelitis and multiple sclerosis in children. Brain. 2000;123(Pt 12):2407-2422.

28. Kennedy PGE, Chaudhuri A. Herpes simplex virus encephalitis. J Neurol Neurosurg Psychiatry. 2002;73:237238.

29. De Tiege X, Rozenberg F, Heron B. The spectrum of herpes simplex encephalitis in children. Eur J Paediatr Neurol. 2008;12(2):72-81.

30. Whitley RJ, Kimberlin DW. Herpes simplex encephalitis: children and adolescents. Semin Pediatr Infect Dis. 2005;16(1):17-23.

31. Al-Shekhlee A, Kocharian N, Suarez JJ. Re-evaluating the diagnostic methods in herpes simplex encephalitis. Herpes. 2006;13(1):17-19.

32. Salih MAM, El Khashab HY, Hassan HH, Kentab AY, Al Subaei SS, Zeidan RM, Al-Nasser1 MN, et al. A study on herpes simplex encephalitis in 18 children, including 3 relapses. The Open Pediatric Medicine Journal. 2009;3:4857.

33. Lakeman FD, Whitley RJ. Diagnosis of herpes simplex encephalitis: application of polymerase chain reaction to cerebrospinal fluid from brain-biopsied patients and correlation with disease. National Institute of Allergy and Infectious Diseases Collaborative Antiviral Study Group. J Infect Dis. 1995;171(4):857-863.

34. Dupuis O, Audibert F, Fernandez H, Frydman R. Herpes simplex virus encephalitis in pregnancy. Obstet Gynecol. 1999;94(5 Pt 2):810-812.

35. Griffin DE. Encephalitis, myelitis, and neuritis. In: Mandell GL, Bennett JE, Dolin R, (Eds), Churchill Livingstone, Philadelphia. 2000. p. 1009-1016. 